\title{
A novel elevation phase elimination method for PSInSAR in urban area with high buildings
}

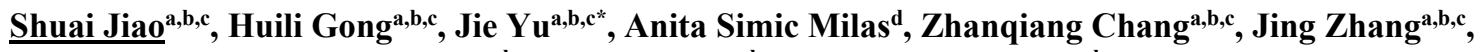

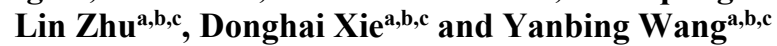 \\ ${ }^{a}$ College of Resource Environment and Tourism, Capital Normal University, Beijing 100048, China \\ ${ }^{b}$ State Key Laboratory Incubation Base of Urban Environmental Processes and Digital Simulation, Beijing \\ 100048, China \\ ${ }^{c}$ Beijing Key Laboratory of Resource Environment and Geographic Information System, Beijing 100048, \\ China \\ ${ }^{d}$ School of Earth, Environment and Society, Bowling Green State University, Ohio, USA \\ Email: jfire2009@,163.com
}

\begin{abstract}
The terrain phase elimination is a key step in the Permanent Scatterer Interferometric SAR technique (PSInSAR) for monitoring land deformation. The Shuttle Radar Topography Mission digital elevation model (SRTM DEM) is widely used. In high-rise urban areas, there are main effects that high buildings have on land subsidence where SRTM DEM is applied: after temporal and spatial filtering, a portion of the terrain phase errors propagates in the residual phase, which directly affects the precision of the land subsidence estimation. In this study, we propose a new method to minimize the errors. We have created a digital surface model (DSM) by overlying SRTM DEM with the layer of the building height obtained by SAR tomography. To validate the proposed approach, the land subsidence was calculated using the SRTM DEM and DSM correction methods. Based on the benchmarks used in the comparison, we show that the elevation phase elimination using DSM leads to more precise measurements of land subsidence rates.
\end{abstract}

Keywords: PSInSAR, TomoSAR, DEM, DSM 
$\underline{\text { Shuai Jiao, }}$ Huili Gong, Jie Yu, Anita Simic Milas, Zhanqiang Chang, Jing Zhang, Lin Zhu, Donghai Xie and Yanbing Wang, A novel elevation phase elimination method for PSInSAR in urban area with high buildings

\section{INTRODUCTION}

In recent years, SAR interferometry (InSAR) has developed into a potential tool for monitoring land subsidence (Graham 1974). The Permanent Scatterer InSAR (PSInSAR) technique has become a potentially unique tool for accurate monitoring of land displacements over large areas (Ferretti, Prati, and Rocca 2001). The advantages of PSInSAR are the reduction of the space and time decoherence, a smaller influence of atmospheric delay, with the capability of providing accurate sequence of PS deformation (Ferretti, Prati, and Rocca 2001; Colesanti et al. 2003).

Terrain phase elimination is a key step in PSInSAR process (He, 2014). Shuttle Radar Topography Mission digital elevation model (SRTM DEM) is widely used in PSInSAR for terrain phase elimination (Chen et al., 2015). Following the accumulation of stacks of SAR images, terrain phase is estimated as a parameter in PSInSAR process $(\mathrm{He}, 2014)$. However, in urban area the impact of high buildings on land subsidence because of the building height beyond the terrain is not effectively eliminated using the SRTM DEM (Li et al., 2016).

The multi-baseline SAR Tomography, which is another extension of the PSInSAR technique, is capable to solve the ambiguity due to multiple scatterers inside a resolution cell and acquisition of each scatterers' height (Reigber and Moreira 2000; Fornaro, Serafino, and Soldovieri 2003). Fornaro, Lombardini, and Serafino (2005) expanded the concept of SAR Tomography by using the Singular-Value-Decomposition (SVD) based approach to estimate the azimuth-height profiles of reconstruction of the San Paolo stadium. Zhu and Bamler (2010) reconstructed a 3D map of Las Vegas Convention Center using the SVD and the Wiener-type regularization methods. Zhu and Bamler (2012) found that L1 norm Minimization, Model selection, and Estimation Reconstruction (SL1MMER) is more precise in height reconstruction, compared with other approaches, such as Beamforming, SVD, and spectrum estimation algorithm. SL1MMER is proven the ability of building height extraction in urban area.

In this paper, we aim at proposing a new method to reduce the phase error caused by building height beyond ground in terrain phase elimination within the PSInSAR processing chain. We create a digital surface model (DSM) by overlying SRTM DEM with the layer of the building height obtained by SAR tomography. DSM is used in terrain phase elimination of PSInSAR process instead of SRTM DEM.

\section{STUDY AREA AND DATASET}

\subsection{Study area}

Beijing is the capital of China and one of the most populous cities in the world with a population of over 20 million. The study site, the Central Business District (CBD), is located within the Chaoyang District and occupies an area of $2 \times 2.5 \mathrm{~km}$ (Figure 1). There are 17 skyscrapers higher than $150 \mathrm{~m}$. Average heights of other high-rise buildings range between 100 and $150 \mathrm{~m}$. Two out of seventeen subway lines provide transport service in the study area. More high-rise buildings and subways are expected to be built in the next decade.

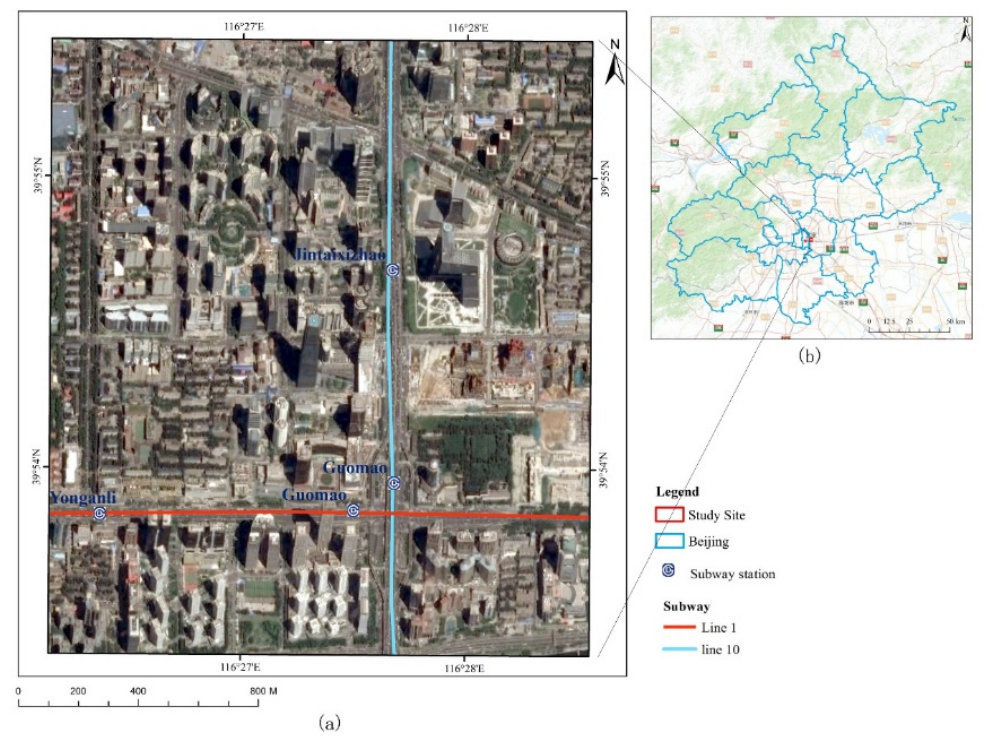

Figure 1. Study site (a) Location of study area, (b) Location of Beijing 
Shuai Jiao, Huili Gong, Jie Yu, Anita Simic Milas, Zhanqiang Chang, Jing Zhang, Lin Zhu, Donghai Xie and Yanbing Wang, A novel elevation phase elimination method for PSInSAR in urban area with high buildings

\subsection{Dataset}

\subsubsection{SAR images}

The method proposed in this paper was applied to TerraSAR-X satellite images. TerraSAR-X is an active radar satellite sensor launched by German Aerospace Center (DLR) on June 15, 2007. TerraSAR-X operates in three modes: SpotLight (up to $1 \mathrm{~m}$ resolution), StripMap (up to $3 \mathrm{~m}$ resolution), and ScanSAR (up to $16 \mathrm{~m}$ resolution) (Suess et al. 2002). The 3D imaging was applied to a real data stack associated with 33 TerraSAR-X images acquired in StripMap mode over the period between 2010 and 2013. The images had both the ground and azimuth range resolutions of $3.0 \mathrm{~m}$. The height of the satellite acquiring radar data according to the master image was defined as $0 \mathrm{~m}$.

The image acquired on April 8, 2012 was chosen to be the master image. The other 32 images were coregistered to the master image at the subpixel level. The spatial baselines are unevenly distributed in elevation direction and the maximum spatial baseline span is less than 500 meters.

\subsubsection{SRTM DEM}

Shuttle Radar Topography Mission (SRTM) is designed under the cooperation of National Aeronautics and Space Administration (NASA), the National Institute of Surveying and Mapping (NIMA), and the German and Italian space agencies. "Endeavor" space shuttle equipped with SRTM system is launched by the United States. The mapping mission lasted from February 11, 2000 to the end of February 22, covering the area of 119 million square kilometers from the north and south of 69 latitude, i.e. more than $80 \%$ of the Earth's land surface. After more than two years of data processing, the digital terrain elevation model (DEM) has been finalized. SRTM products in 2003 began public release and V4.1 is the latest version. The spatial resolution is $90 \times 90$ meter.

\section{METHOD}

\subsection{Digital surface model generation}

Multi-baseline SAR Tomography is an extension to PSInSAR, with the ability of solving the ambiguity related to a large amount of persistent scatterers (PS) in dense urban areas with more than one dominant scatterer in elevation direction (Balz et al. 2012).

With SAR uneven passes, the acquisition of each pass can be written in the following way (Fornaro, Serafino, and Soldovieri 2003):

$$
\mathrm{g}_{\mathrm{n}}=\int_{\Delta \mathrm{s}} \gamma(\mathrm{s}) \exp \left(-\mathrm{j} 2 \pi \xi_{\mathrm{n}} \mathrm{s}\right) \mathrm{ds}, \quad \mathrm{n}=1, \ldots, \mathrm{N}
$$

where $\gamma(\mathrm{s})$ is the reflectivity function along with the elevation direction $\mathrm{s}$; $\xi \mathrm{n}$ is the spatial (elevation) frequency. The space system model (equation (1)) can be further approximated as (Zhu and Bamler 2009):

$$
\mathrm{g}=\mathbf{R} \gamma(2)
$$

where $g$ is the measurement vector with $\mathrm{N}$ elements, $\mathrm{R}$ is an $\mathrm{N} \times \mathrm{L}$ mapping matrix with $\mathbf{R}_{\mathrm{nl}}=\exp \left(-\mathrm{j} 2 \pi \xi_{\mathrm{n}} \mathrm{s}_{\mathrm{l}}\right)$, and $\gamma$ is the discrete reflectivity vector with L elements $\left(\Upsilon_{l}=\Upsilon\left(s_{l}\right)\right.$, and $s_{l}(l=1 \ldots L)$ is the discrete elevation position.

The main objective of the SAR tomography is to retrieve the reflectivity profile for each azimuth-range spatial resolution of pixels. To reconstruct the reflectivity profile, we used SL1MMER (Zhu and Bamler 2012) to combine parametric estimation and non-parametric estimation to get better elevation accuracy. Within this process, the compressive sensing was used as a powerful approach for sparse signal reconstruction, where the process of elevation profile reconstruction was reduced to a minimum 11 norm reconstruction (Zhu and Bamler 2009):

$$
\min \|\Upsilon\|_{1} \quad \text { s. } \mathbf{t} . \mathrm{y}=\mathbf{R} \Upsilon+\mathrm{n}_{0}
$$

where $\mathrm{n}_{0}$ is observation noise.

The model order selection is a process of using a maximum-likelihood estimator (MLE) to evaluate the number of scatterers with three parameters (height, phase and amplitude). The penalty term was added to avoid overfitting the data. The equation is shown as (Zhu and Bamler 2010):

$$
\widehat{\mathrm{K}}=\arg \min _{\mathrm{K}}\{-2 \operatorname{lnp}(\mathrm{g} \mid \widehat{\theta}(\mathrm{K}), \mathrm{K})+2 \mathrm{C}(\mathrm{K})\}
$$


Shuai Jiao, Huili Gong, Jie Yu, Anita Simic Milas, Zhanqiang Chang, Jing Zhang, Lin Zhu, Donghai Xie and Yanbing Wang, A novel elevation phase elimination method for PSInSAR in urban area with high buildings

where $\mathrm{C}(\mathrm{K})$ is the complexity penalty, $\mathrm{K}^{\wedge}$ is the estimated number of scatters in one pixel, $\hat{\theta}$ is estimated vector of the unknown amplitudes, phases and elevations, $\mathrm{g}$ is the observed value and $\mathrm{K}$ is number of scatters in one pixel.

Following the equality of the equations $-2 \ln p(\mathrm{~g} \mid \hat{\theta}(\mathrm{K}), \mathrm{K})=\sigma_{\varepsilon}^{2}\|\mathrm{~g}-\mathbf{R} \hat{\gamma}\|_{2}^{2}$, the elevation profile was derived as (Zhu and Bamler 2012):

$$
\hat{\gamma}(\widehat{\mathrm{s}})=\left(\mathbf{R}^{\mathrm{H}}(\widehat{\mathrm{s}}) \mathbf{R}(\widehat{\mathrm{s}})\right)^{-1} \mathbf{R}^{\mathrm{H}}(\widehat{\mathrm{s}}) \mathrm{g}
$$

Finally, the elevation profile was obtained without possible outliers, improving the result of the direct compressive sensing progress.

In order to overlay building height and SRTM DEM, height result points are coregistered to the same coordination with SRTM DEM and transformed to building height polygon using building footprint feature. After rasterization, building height raster with the same cell size of SRTM DEM can be overlaid on SRTM DEM to generate DSM.

In this study, height result points are coregistered to UTM 50 projection in ArcMAP (GIS software of ESRI). Choose the points included in the building footprint drawn according to Google Earth and the height of the building is the average height of selected points. Digtal surface model can be obtained by combining building height and the DN value of SRTM DEM.

\subsection{Elimination of terrain phase in PSInSAR using DSM}

Terrain phase elimination is the key step of PSInSAR. SRTM DEM is widely used in common PSInSAR process to eliminate the error caused by the terrain. In this study, we use the DSM obtained by SAR tomography instead of SRTM DEM.

StaMPS (Hooper et al. 2004), is applied in our study to obtain land subsidence rate for the advantage on improving the number of available interferograms and time resolution.

\section{RESULT AND DISCUSSION}

\subsection{DSM created by SAR Tomography}

The scatterers are precisely adjusted to Gauss-Kruger projection $21 \mathrm{~N}$ strip from radar coordinate using ArcMap (ESRI) and are clipped by building footprint map drawn according to Google Earth, as shown in Figure 2. The gray features are building footprints drawn according to Google Earth. In the area, the highest building scatterer is $343 \mathrm{~m}$ and the lowest scatterer is on the ground $(0 \mathrm{~m})$.

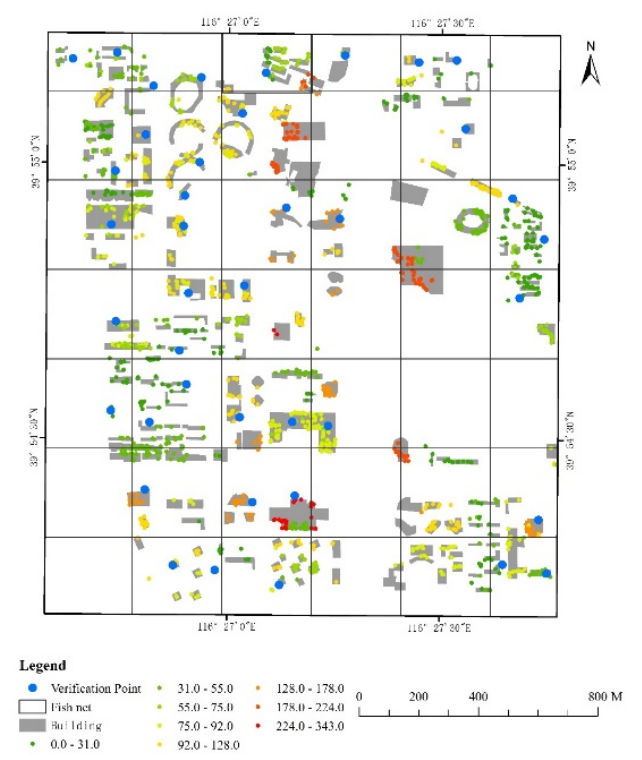

Figure 2. The heights of scatterers generated for the study area

To validate the scatterer height, a $100 \mathrm{~m} \times 100 \mathrm{~m}$ fish net is created to sample the point heights (Figure 2). Forty scatterers are chosen to validate the height results, according to the number of scatterers in each fish net cell. 
Shuai Jiao, Huili Gong, Jie Yu, Anita Simic Milas, Zhanqiang Chang, Jing Zhang, Lin Zhu, Donghai Xie and Yanbing Wang, A novel elevation phase elimination method for PSInSAR in urban area with high buildings

Two scatterers are chosen when the number of scatterers in one fish net cell is higher than the average value of 81.4 (1362 scatterers distributing in 42 fish nets), and one scatterer is chosen when the number of scatterers in one fish net cell is lower than the average value of 81.4. Compared with the height data (Measured by GPS according the scatterer geo-coordinate), the results obtained by SL1MMER have an error ranging from $-6 \mathrm{~m}$ to $7 \mathrm{~m}$ with a mean error value of $3.675 \mathrm{~m}$.

After coregistration of PSs with building height, building footprint map is used to create building height.

For the buildings with regular vertical shapes, the volume are calculated by multiplying the building heights and footprint areas, while for the buildings with irregular vertical shapes, the footprints are divided into different parts according to building height prior to the calculations.

DSM is obtained by combining building height and SRTM DEM in the study area (Figure 3).

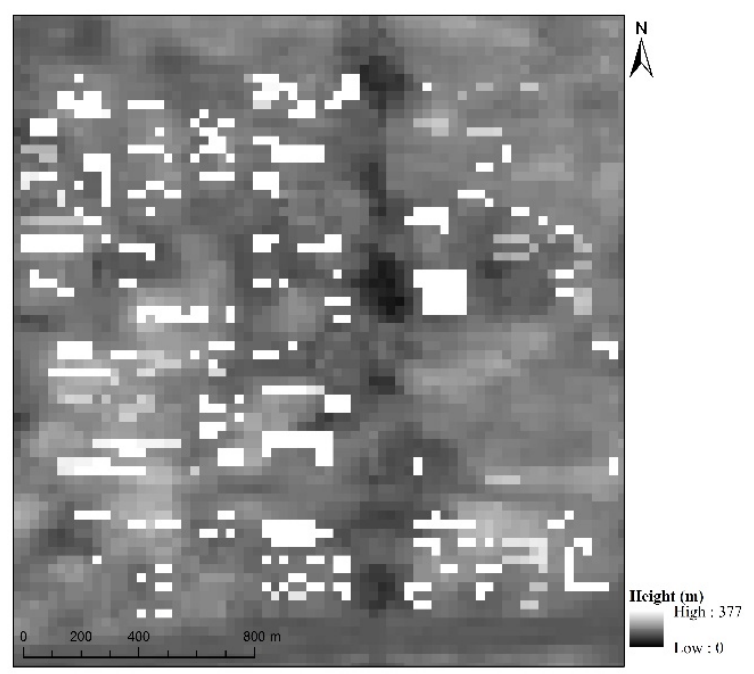

Figure 3. DSM obtained by SAR tomography

\subsection{Land subsidence comparison under terrain phase elimination using DSM and DEM}

We have coregistered two results using DSM obtained by SAR tomography and SRTM DEM to UTM 50 zone projection (Figure 4). There are somewhat differences in location between the results using DSM and SRTM DEM. When the terrain phase is eliminated using SRTM DEM, the buildings on the terrain are ignored, leading the offsets of PSs location in geo-coordination after geo-coding in PSInSAR progress. The locations offset of PSs tend to decrease using the DSM obtained by SAR tomography.

Finally, we have calculated the land subsidence rate around two benchmarks and compared the results with the average land subsidence of PSs located at a distance less than $200 \mathrm{~m}$ around the benchmarks (Table 1). The subsidence values using DSM are smaller than those obtained with SRTM DEM, with a smaller difference $(2.97 \mathrm{~mm} / \mathrm{yr}$ instead of $3.32 \mathrm{~mm} / \mathrm{yr})$ with respect to the true benchmark records suggesting that the results using DSM is somewhat more accurate than those using SRTM DEM.

Table 1. The difference of land subsidence between benchmarks and PSs

\begin{tabular}{|c|c|c|c|c|c|}
\hline & \multirow{2}{*}{$\begin{array}{l}\text { Benchmark } \\
(\mathrm{mm} / \mathrm{yr})\end{array}$} & \multicolumn{2}{|c|}{ Average value of PSs around bench $\operatorname{mark}(\mathrm{mm} / \mathrm{yr})$} & \multicolumn{2}{|c|}{ Difference $(\mathbf{m m} / \mathbf{y r})$} \\
\hline & & Using DSM & Using SRTM & Using DSM & Using SRTM \\
\hline $\mathrm{B} 1$ & -4.75 & -7.54 & -7.83 & 2.79 & 3.08 \\
\hline B2 & -15.40 & -18.55 & -18.97 & 3.15 & 3.57 \\
\hline
\end{tabular}


Shuai Jiao, Huili Gong, Jie Yu, Anita Simic Milas, Zhanqiang Chang, Jing Zhang, Lin Zhu, Donghai Xie and Yanbing Wang, A novel elevation phase elimination method for PSInSAR in urban area with high buildings

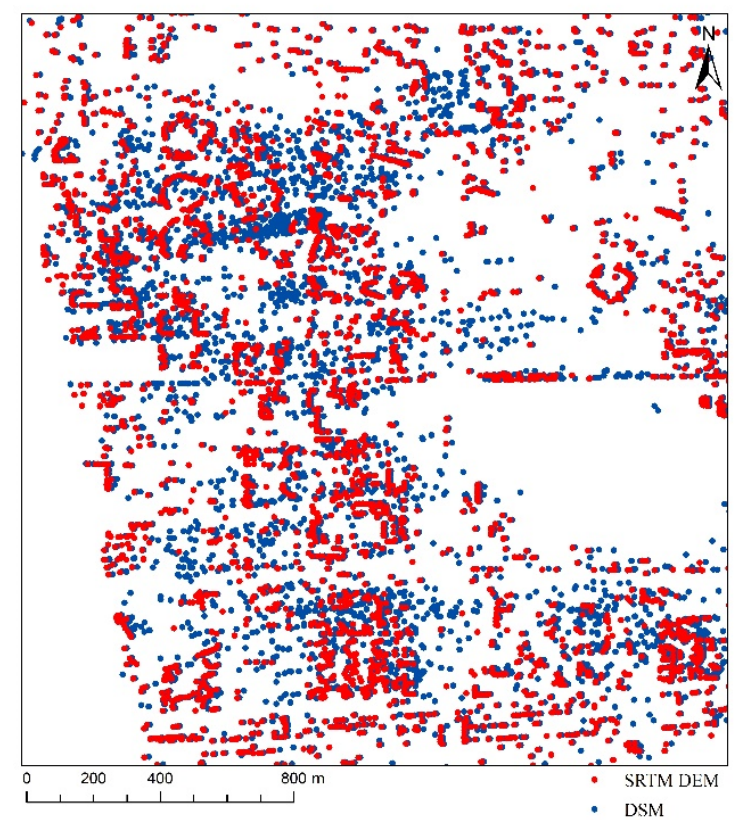

Figure 4. Land subsidence comparison under terrain phase elimination using DSM (blue points) and SRTM DEM (red points).

\section{CONCLUSION}

In this paper, we proposed an original method using DSM overlaying building height obtained by SAR tomography and SRTM DEM to eliminate the terrain phase in PSInSAR process. Our study demonstrates that SL1MMER is effective in calculating building height for areas with high building, hence to create DSM by combining SRTM DEM. Using DSM instead of SRTM DEM effectively reduces the error caused by the high buildings in urban area.

\section{ACKNOWLEDGEMENTS}

This work was funded by the National Natural Science Foundation of China (Grant No.41671417).

\section{REFERENCES}

Aiazzi B, Baronti S, Selva M, Alparone L Enhanced Gram-Schmidt spectral sharpening based on multivariate regression of MS and pan data. In: Geoscience and Remote Sensing Symposium, 2006. IGARSS 2006. IEEE International Conference on, 2006. IEEE, pp 3806-3809.

Amelung F, Galloway DL, Bell JW, Zebker HA, Laczniak RJ (1999). Sensing the ups and downs of Las Vegas: InSAR reveals structural control of land subsidence and aquifer-system deformation Geology 27:483-486.

Balz T, Wei L, Jendryke M, Perissin D, Liao M Tomosar and PS-InSAR analysis of high-rise buildings in Berlin. In: Igarss, 2012. pp 447-450.

Chen B, Gong H, Li X, Lei K, Ke Y, Duan G, Zhou C (2015). Spatial correlation between land subsidence and urbanization in Beijing, China Natural Hazards 75:2637-2652.

Colesanti C, Ferretti A, Prati C, Rocca F (2003). Monitoring landslides and tectonic motions with the Permanent Scatterers Technique Engineering Geology 68:3-14.

Ferretti A, Prati C, Rocca F (2001). Permanent scatterers in SAR interferometry Geoscience and Remote Sensing, IEEE Transactions on 39:8-20.

Fornaro G, Lombardini F, Serafino F (2005). Three-dimensional multipass SAR focusing: Experiments with long-term spaceborne data Geoscience and Remote Sensing, IEEE Transactions on 43:702-714.

Fornaro G, Serafino F, Soldovieri F (2003). Three-dimensional focusing with multipass SAR data Geoscience and Remote Sensing, IEEE Transactions on 41:507-517. 


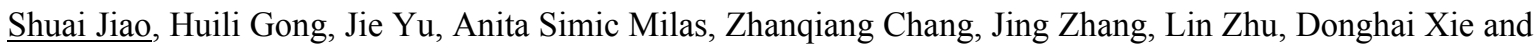
Yanbing Wang, A novel elevation phase elimination method for PSInSAR in urban area with high buildings

Graham LC (1974). Synthetic interferometer radar for topographic mapping Proceedings of the IEEE 62:763768.

He ping. (2014). Error analysis and surface deformation application of time series InSAR. Dissertation. Wuhan University.

Hooper A, Zebker H, Segall P, Kampes B (2004). A new method for measuring deformation on volcanoes and other natural terrains using InSAR persistent scatterers Geophysical research letters 31.

Lesniak A, Porzycka S (2009). Geostatistical computing in PSInSAR data analysis. In: Computational Science-ICCS 2009. Springer, pp 397-405.

Lewis RW, Schrefler B (1978). A fully coupled consolidation model of the subsidence of Venice Water Resources Research 14:223-230.

Li Yingchen, Ke Yinghai, Gong Huili, Li Xiaojuan, Chen Beibei, Liang Yuanchuan, Jin Xi (2016). Differences of PS-InSAR monitoring of ground subsidence using multi-source DEM. Science of Surveying and Mapping: In Press.

Massonnet D, Rossi M, Carmona C, Adragna F, Peltzer G, Feigl K, Rabaute T (1993). The displacement field of the Landers earthquake mapped by radar interferometry Nature 364:138-142.

Poland JF, Davis GH (1969). Land subsidence due to withdrawal of fluids Reviews in engineering geology 2:187-270.

Pratt WE, Johnson DW (1926). Local subsidence of the Goose Creek oil field The Journal of Geology:577590

Reigber A, Moreira A (2000). First demonstration of airborne SAR tomography using multibaseline L-band data Geoscience and Remote Sensing, IEEE Transactions on 38:2142-2152.

Suess M, Riegger S, Pitz W, Werninghaus R TerraSAR-X-design and performance. In: Proc. EUSAR, 2002. pp 49-52.

Zhu L, Gong H, Li X, Wang R, Chen B, Dai Z, Teatini P (2015). Land subsidence due to groundwater withdrawal in the northern Beijing plain, China Engineering Geology 193:243-255.

Zhu X, Bamler R Very high resolution SAR tomography via compressive sensing. In: Proc. ESA FRINGE Workshop Adv. Sci. Appl. SAR Interferometry, 2009.

Zhu X, Bamler R (2010). Very high resolution spaceborne SAR tomography in urban environment Geoscience and Remote Sensing, IEEE Transactions on 48:4296-4308.

Zhu X, Bamler R (2012). Super-resolution power and robustness of compressive sensing for spectral estimation with application to spaceborne tomographic SAR Geoscience and Remote Sensing, IEEE Transactions on 50:247-258. 